\title{
MICROSTRUCTURE INVESTIGATION AND MECHANICAL PROPERTIES OF Ti-6AI-2Sn-4Zr- 6Mo ALLOY PROCESSED BY HOT ROLLING AND SOLUTION TREATMENT
}

\author{
'Mohammed Hayder ALLUAIBI, 'Saleh Sabah ALTURAIHI, 'Doina RADUCANU, '2Adrian RUSEA, \\ ${ }^{1}$ Ion CINCA, ${ }^{3}$ Anna NOCIVIN, ${ }^{1}$ Vasile Danut COJOCARU
}

\author{
1POLITEHNICA University of Bucharest, Romania, mohammed.aluaibi@gmail.com \\ 2SC ZIROM SA, Giurgiu, Romania, adrian.rusea@zirom.ro \\ ${ }^{3}$ OVIDIUS University of Constanta, Romania, anocivin@univ-ovidius.ro
}

https://doi.org/10.37904/metal.2020.3580

\begin{abstract}
The Ti-6Al-2Sn-4Zr-6Mo (Ti-6246) titanium alloy is categorized as one of $\alpha+\beta$ titanium alloys group, which plays an important role in the aerospace applications. This study aims to find out the optimal thermomechanical processing route to obtain a good balance of strength, ductility and fracture toughness. The Ti-6246 alloy was hot-deformed at a temperature of $900^{\circ} \mathrm{C}$, with a total deformation degree of approximately $60 \%$, and heattreated by a solution treating at temperatures between $800^{\circ} \mathrm{C}-1000^{\circ} \mathrm{C}$ for 18 minutes. The microstructural evolution, mechanical properties and fractography analysis were investigated. Results revealed that the volume fraction of the primary $\alpha\left(\alpha_{p}\right)$ phase decreases progressively until it is completely dissolved with increasing solution temperature; the secondary $\alpha\left(\alpha_{s}\right)$ phase increases whereas its width decrease with increasing solution temperature, and also the yield stress and ultimate tensile strength decrease with increasing solution temperature. A good balance of ultimate tensile strength and ductility was obtained in the case of a solution temperature of $900^{\circ} \mathrm{C}$, which showed a tensile strength close to $812 \pm 4 \mathrm{MPa}$ and an elongation close to $11.1 \pm 2.4 \%$. The fine $\alpha_{s}$ phase facilitates the paths of crack propagation, meaning decrease the crack propagation resistance and decrease the ductility and fracture toughness.
\end{abstract}

Keywords: Titanium alloy, microstructure, mechanical properties

\section{INTRODUCTION}

Titanium alloys are promised materials for various applications fields, owing to their good chemical and mechanical properties [1]. The titanium alloys that have $\alpha+\beta$ type are usually sensitive to processing parameters. Therefore, the microstructures and mechanical properties are affected by hot deformation and heat treatment to optimization them, and this matter is receiving great attention from the researchers [24].Earlier attempts were made to study the plasticity of $\alpha+\beta$ alloys which are reviewed in [5]. Moreover, it was found that the yield strength of titanium-based alloys that have a duplex structure, which is equiaxed a plus transformed $\beta$, depends on the local yield of the equiaxed a particles, whereas work hardening depends on the slip transfer from the equiaxed $\alpha$ to the stronger transformed $\beta$ and its subsequent deformation [6]. The application of the law of mixtures to predict plastic properties is generally not correct, due to several complex factors like the interaction between the equiaxed $\alpha$ and transformed $\beta[7,8]$. This experiment provides a good insight into the evolution of plasticity in the Ti-6Al-2Sn-4Zr-6Mo titanium alloy by studying the changes in the microstructure and mechanical properties of this alloy.

\section{EXPERIMENTAL PROCEDURES}

\subsection{Alloy and sampling method}

This experiment utilized Ti-6Al-2Sn-4Zr-6Mo (Ti-6246) titanium alloy provided by S.C. ZIROM S.A., Giurgiu, Romania, which was obtained by Vacuum Arc Remelting (VAR). The Ti-6246 titanium alloy has a chemical 
composition computed by weight as listed in Table 1. The elements that have a very slight quantitative trace were neglected. An unprocessed portion of the Ti-6246 titanium alloy was taken; also three billets were cut from this alloy and subjected it to the thermomechanical processing as well as to conduct microstructure examination and mechanical properties. All cutting operations were performed for samples using a BERNARDO MBS 280DGand a precision cutter - Metkon Micracut 200.

Table 1 Computed chemical composition of the initial state for Ti-6246 titanium alloy

\begin{tabular}{|c|c|c|c|c|c|c|c|}
\hline Element & At. No. & Line s. & Netto & Wt $\%$ & At\% & Abs. error (\%) & Rel. error (\%) \\
\hline Titanium & 22 & K-Serie & 52341150 & 82.505 & 83.640 & 2.47 & 2.79 \\
\hline Aluminum & 13 & K-Serie & 4831607 & 5.835 & 10.497 & 0.32 & 5.17 \\
\hline Molybdenum & 42 & L-Serie & 3962998 & 5.743 & 2.906 & 0.24 & 3.94 \\
\hline Zirconium & 40 & L-Serie & 2532633 & 3.912 & 2.081 & 0.18 & 4.38 \\
\hline Tin & 50 & L-Serie & 1230486 & 1.883 & 0.770 & 0.08 & 4.18 \\
\hline Iron & 26 & K-Serie & 46297 & 0.122 & 0.106 & 0.03 & 21.78 \\
\hline \multicolumn{2}{r|}{} & & Sum & 100 & 100 & \multicolumn{2}{|l}{} \\
\hline
\end{tabular}

\subsection{Thermomechanical processing route of Ti-6246 titanium alloy}

Thermomechanical processing route of Ti-6246 titanium alloy is presented in Figure 1. The retention time in the furnace to all samples before the rolling mill process was 1.5 minutes per $1 \mathrm{~mm}$ of the thickness. The number of passes (n) was 4 passes and in each pass, the reduction in thickness was $1 \mathrm{~mm}$ to all samples. The initial dimensions of all samples were of $69 \mathrm{~mm}$ length, $13 \mathrm{~mm}$ width and $7 \mathrm{~mm}$ thickness. This alloy is hot rolled in the $\alpha+\beta$ phase field with no lubrication, followed by a solution treatment at the $\alpha+\beta$ and $\beta$ phases fields with a cooling rate more than $100^{\circ} \mathrm{C} / \mathrm{s}$ in oil. This processing route aims to explore the different aspects of the microstructure investigation and mechanical properties. The hot deformation by the rolling mill was carried out using a "UM. Progresul Braila" rolling mill. The heat treatment was carried out using a NABERTHERM furnace (high-temperature chamber - 08/16 with SiC rod heating). The total deformation degree during 4 passes for samples processed by the hot rolling-mill has been estimated from Equation (1).

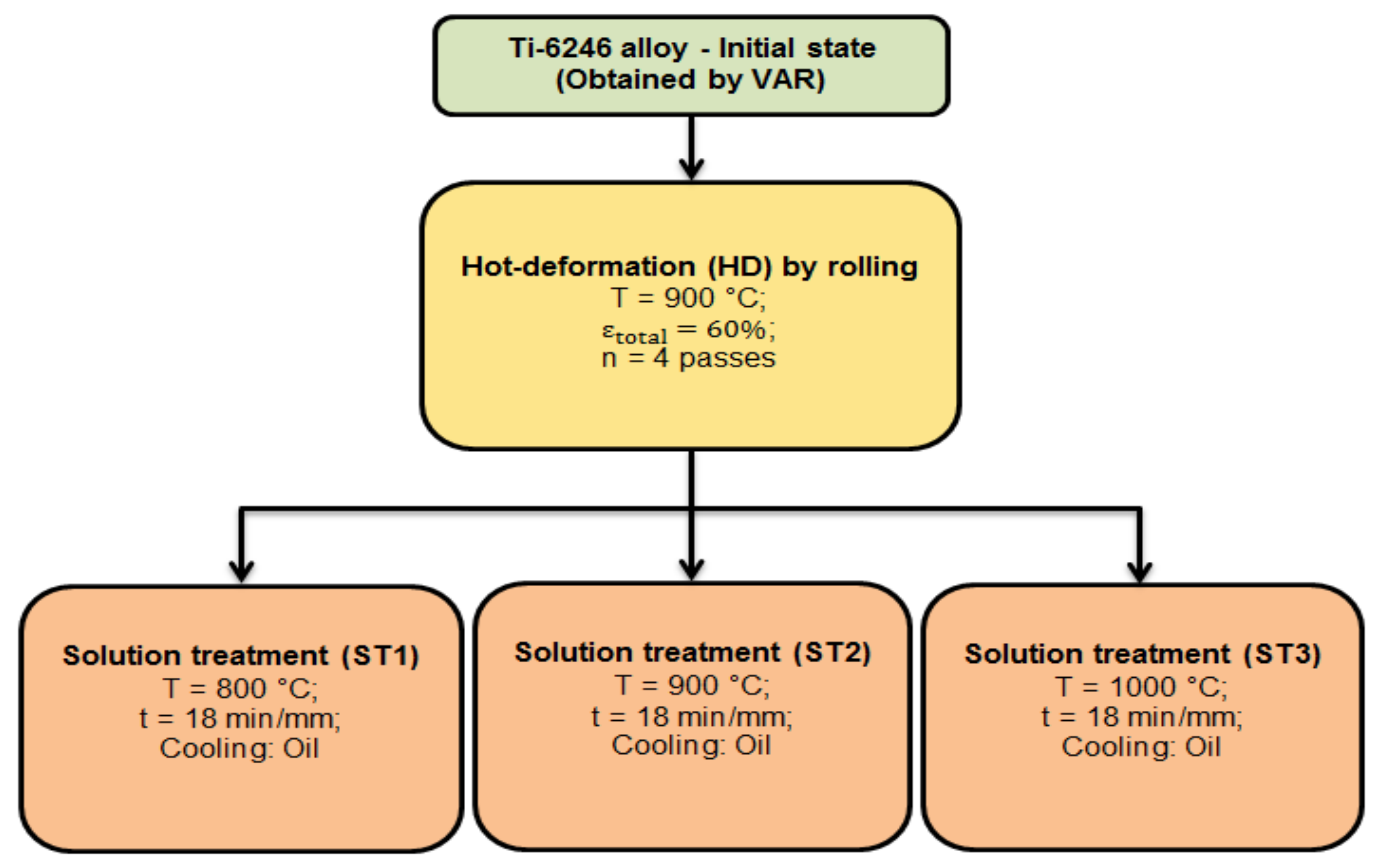

Figure 1 Thermomechanical processing route of Ti-6246 titanium alloy 
$\varepsilon_{t}=\frac{h_{\circ}-h_{f}}{h_{\circ}} * 100(\%)$

where: $\varepsilon_{t}$ - total deformation degree $(\%) ; h_{o^{-}}$initial sample thickness $(\mathrm{mm}) ; h_{f}$ - final sample thickness $(\mathrm{mm})$.

\subsection{Metallography investigation}

All samples were hot mounted in epoxy resin using a BUEHLER SimpliMet hydraulic mounting press, and then they are ground and polished mechanically using a Metkon DIGIPREP Accura. The microstructure of each sample was examined using scanning electron microscopy (SEM) - Tescan VEGA II - XMU. The Ti-6246 titanium alloy phases have been determined using SEM - backscattered electrons (BSE) detector.

\subsection{Mechanical properties and fractography investigation}

All samples were subjected to the tensile test using an electromechanical machine as known as INSTRON 3382. It has been measured the average values of $0.2 \%$ yield strength $\left(\sigma_{0.2 \%}\right)$, the ultimate tensile strength ( $\left.\sigma_{U T S}\right)$ and the total fracture elongation $\left(\varepsilon_{\mathrm{f}}\right)$ to failure. The fractography of each sample was taken from the tensile test samples which were cut into a rectilinear sliced have dimensions approximately $80 \mathrm{~mm}$ length, 5 $\mathrm{mm}$ width and $3 \mathrm{~mm}$ thickness. The fractography investigation was performed using SEM - secondary electrons (SE) detector.

\section{RESULTS AND DISCUSSION}

\subsection{Metallography investigation}

The microstructures observations that are displayed in Figures 2.a - 2.c from low magnification (100 $\mu \mathrm{m})$ to high magnification $(5 \mu \mathrm{m})$ show the phases which are composed within the Ti-6246 titanium alloy: primary $\alpha$ $\left(\alpha_{p}\right)$-Ti phase, secondary $\alpha\left(\alpha_{s}\right)-T i$ and $\beta$-Ti phases which have adapted to each other as an $\alpha+\beta$ lamellar colonies structure. Figures 2.d - $\mathbf{2 f}$ show that the recrystallization process takes place in the microstructure and formation of various grains size. The structure consists of $\alpha_{p}$ in the form of spots and $\alpha_{s}+\beta$ lamellar colonies. Figures 2.g - 2.i it does not show much development in the microstructure as compared to the case that processed at a temperature of $800^{\circ} \mathrm{C}$ and the structure has remained almost the same in the formation. Moreover, Figures 2j - 2l show an important development in the microstructure at a temperature of $1000^{\circ} \mathrm{C}$, which showed fully melting of $\alpha_{p}$ phase and significantly increasing of $\alpha_{s}+\beta$ lamellar colonies, also the formation of a large proportion of $\alpha^{\prime}$ and $\alpha^{\prime \prime}$ martensite phases have thick and thin acicular-like shapes, respectively. The temperature has mainly affected the evolution of the Ti-6246 titanium alloy phases and also on the thickness of $\alpha+\beta$ lamellar colonies as presented in all micrographs of processed states.

\subsection{Mechanical test and fractography investigation}

The mechanical properties values of the initial state and the processed states are presented in Table 2. According to Figure 3, which shows the engineering tensile stress-strain curves and their values in Table 2, it is possible to observe a decrease in the ultimate tensile strength and yield strength and an increase in elongation for the samples affected by thermomechanical processes until elongation decreases significantly at a temperature of $1000{ }^{\circ} \mathrm{C}$ due to the rise in temperature to the $\beta$ phase field and the fully melting of the $\alpha_{p}$ phase and the decrease in $\alpha_{s}$ phase width leading to this significant decrease in the elongation.

The fractographies observations that are displayed in Figures 4.a - 4.c from low magnification $(100 \mu \mathrm{m})$ to high magnification $(10 \mu \mathrm{m})$ show the initial state which its surface consists of dimples, some micro-voids and cleavage facets. The mode of the fracture surface indicates that the initial state of Ti-6246 titanium alloy has high ductility as compared to the processed states. Figures $4 . d$ - 4.f shows cleavage facets, dimples and micro-voids which reveal a mixed behavior of ductility and brittleness. Moreover, it can observe in Figures 4.g - 4.f coalescence a group of the growing micro-voids to form a micro-crack and cleavage facets 
which give it mixed behavior also of ductility and brittleness. Figures $4 . j$ - $4 . I$ shows clearly a lot of cleavage facets along with some micro-cracks and dimples. This state has higher brittleness than the initial and processed states.
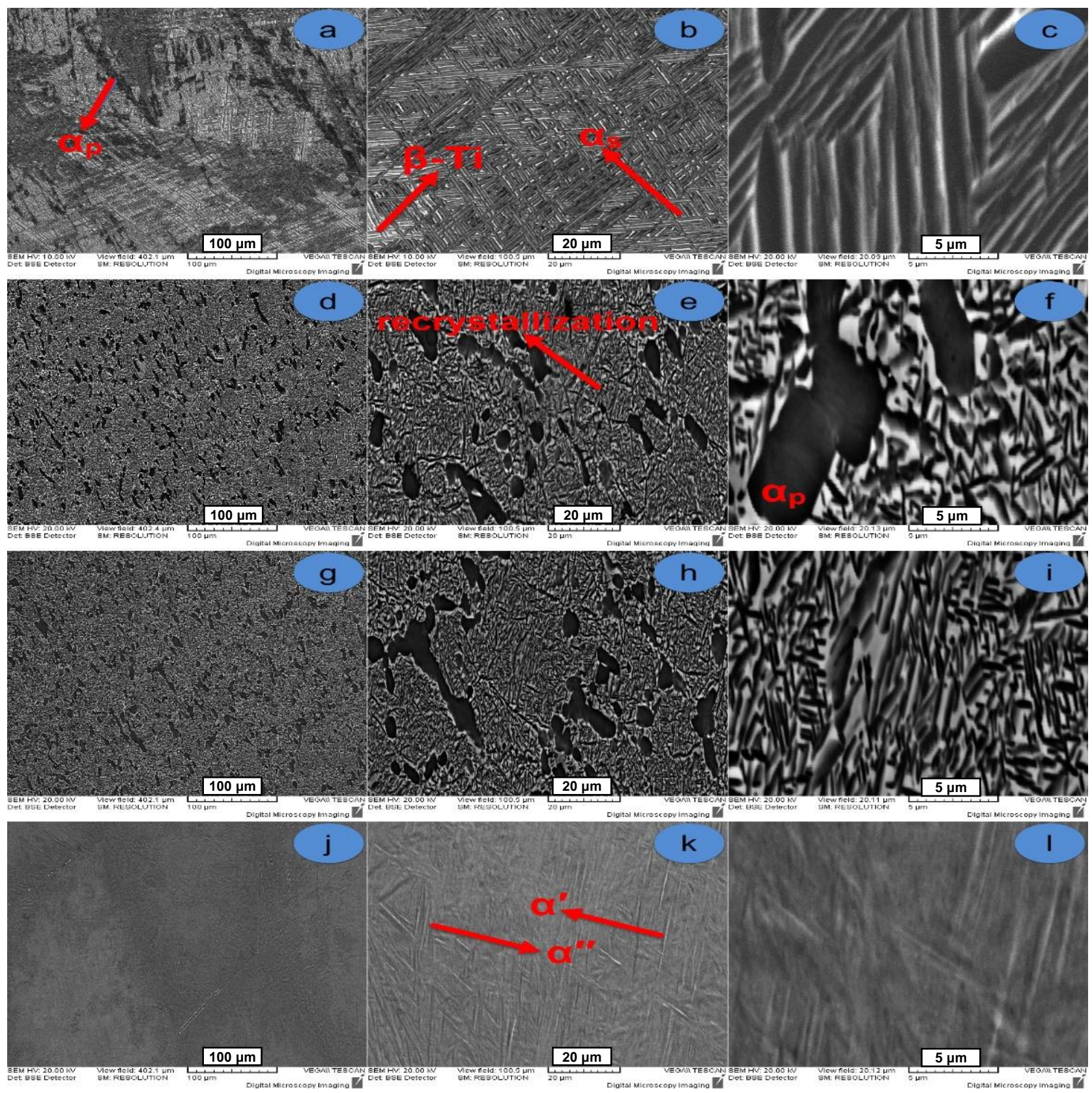

Figure 2 Microstructures by SEM-BSE of all samples; (a-c) initial state, (d-f) HD + ST1, (g-i) HD + ST2, (j-l) $\mathrm{HD}+\mathrm{ST} 3$

Table 2 Measured mechanical properties after thermomechanical processing of Ti-6246 titanium alloy

\begin{tabular}{|c|c|c|c|c|}
\hline Mechanical properties & Initial state & HD + ST1 & HD + ST2 & HD + ST3 \\
\hline Ultimate tensile strength, $\sigma_{\text {uts }}(\mathrm{MPa})$ & $1201 \pm 9$ & $1000 \pm 7$ & $812 \pm 4$ & $514 \pm 3$ \\
\hline Yield strength, $\sigma_{0.2 \%}(\mathrm{MPa})$ & $495 \pm 10$ & $366 \pm 6$ & $212 \pm 5$ & $211 \pm 4$ \\
\hline Fracture elongation, $\varepsilon_{f}(\%)$ & $21.9 \pm 1.3$ & $9.6 \pm 1.4$ & $11.1 \pm 2.4$ & $4.2 \pm 1.1$ \\
\hline
\end{tabular}




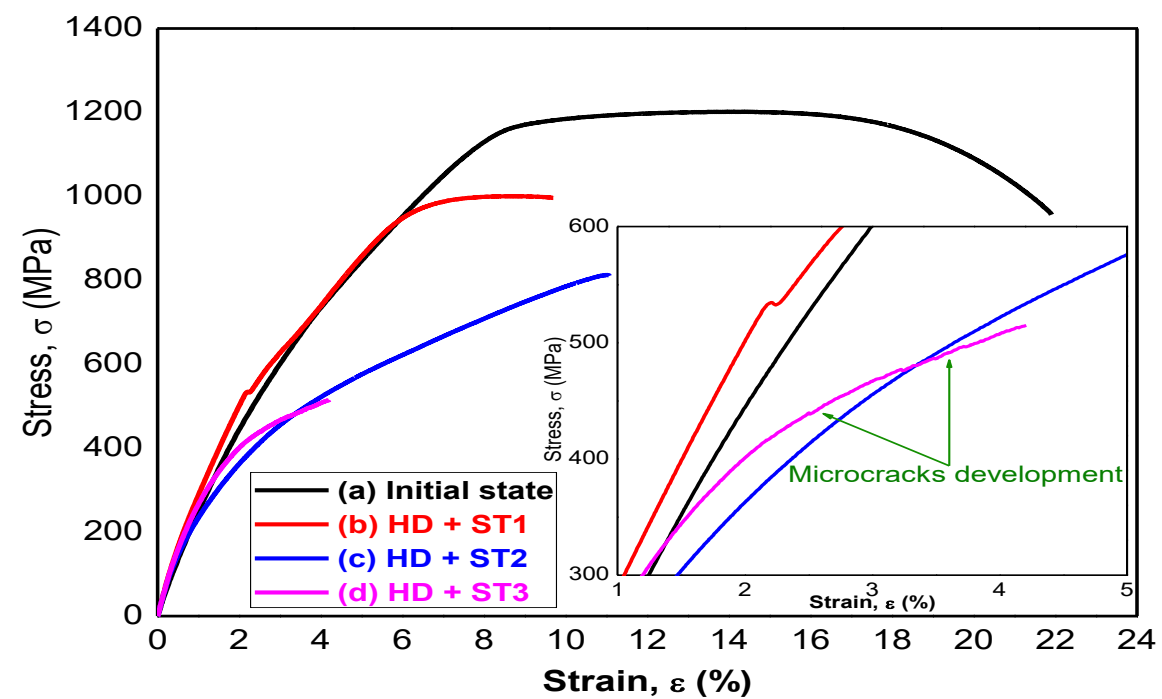

Figure 3 Engineering tensile stress-strain curves of all samples; (a) initial state, (b) HD + ST1, (c) HD + ST2, (d) HD + ST3
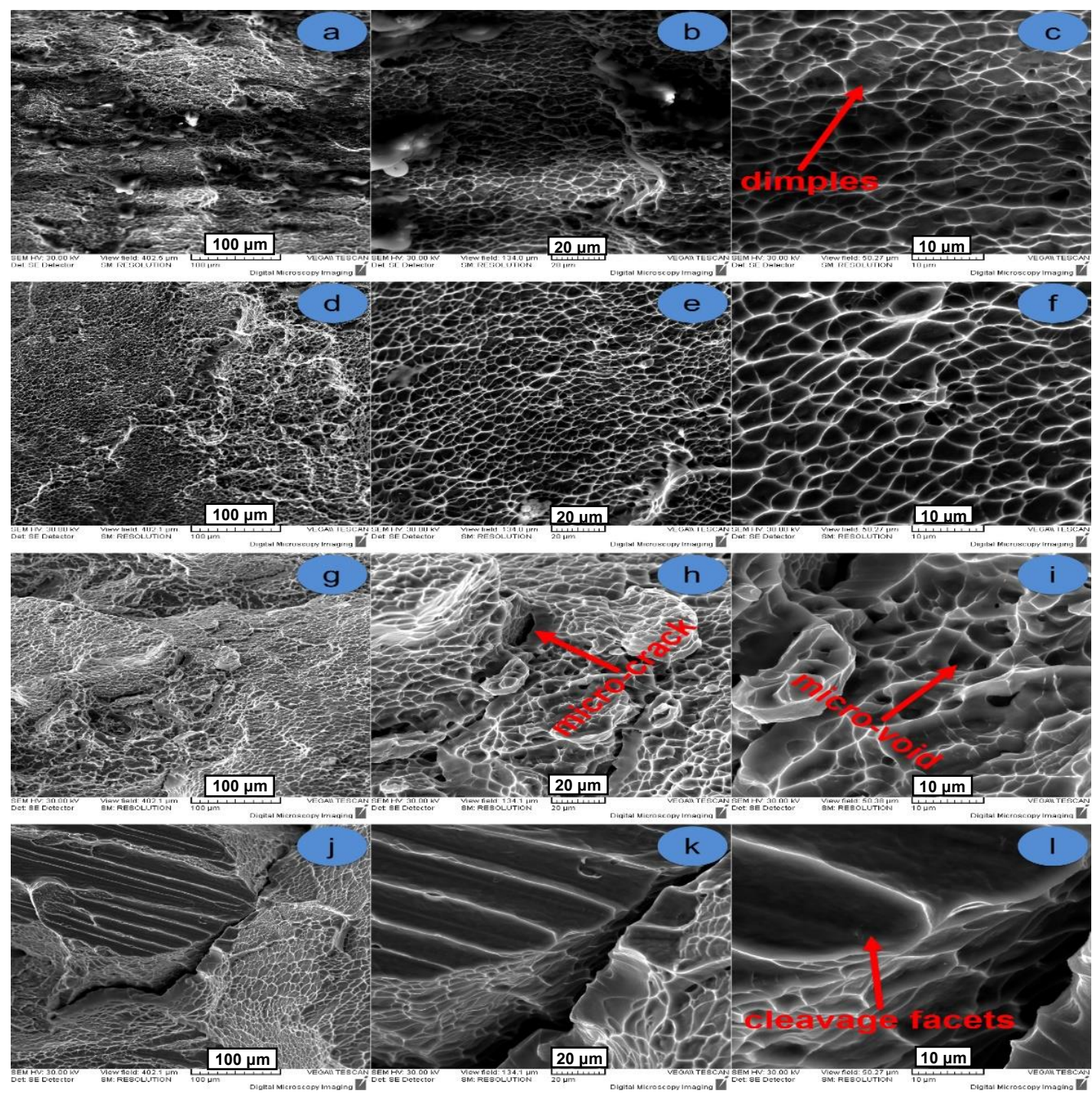

Figure 4 Fractographies by SEM-SE of all samples; (a-c) initial state, (d-f) HD + ST1, (g-i) HD + ST2, (j-I) HD + ST3 


\section{CONCLUSIONS}

The conclusions can be summarized as follows:

- The microstructures have been affected by the temperature of the solution treatment, which mainly designates the evolution of Ti-6246 titanium alloy phases. The increase in the solution temperature decreasing the $\alpha_{p}$ phase until it is completely melting and the $\alpha_{s}$ phase increasing while decreasing its width, led to a decrease in resistance to cracks propagation and consequently a decrease in ductility and the fracture toughness. The presence of a large proportion of the $\alpha^{\prime}$ and $\alpha^{\prime \prime}$ martensite phases at a temperature of $1000^{\circ} \mathrm{C}$ gains the material a more brittle behavior, and this explains the significant drop in ductility.

- $\quad$ The ultimate tensile strength and the yield strength are decreases plus the elongation increase with increasing solution treatment temperature in the $\alpha+\beta$ phase field and it was observed a strong drop in ductility at the $\beta$ phase field. A good balance of strength and ductility was achieved after the solution treatment at a temperature of $900{ }^{\circ} \mathrm{C}$, in which the ultimate tensile strength is $812 \pm 4$ and the fracture elongation is $11.1 \pm 2.4 \%$.

- $\quad$ The fractographies investigations showed different fracture surface modes during thermomechanical processing used in this study. The good ductile mode is observed in the $\alpha+\beta$ phase field, particularly at a solution treatment temperature of $900^{\circ} \mathrm{C}$.

\section{REFERENCES}

[1] LIU, X., YU, D., FAN, Q., SHI, R. Influence of hot rolling and heat treatment on the microstructural evolution of B20C titanium Alloy. Materials. 2017, vol. 10, no. 9, p. 1071.

[2] BO, T., BIN, T., FENGBO, H., GUANJUN, Y., JINSHAN, L. Influence of strain rate on stress induced martensitic transformation in $\beta$ solution treated TB8 alloy. Journal of Alloys and Compounds. 2013, vol. 565, pp. 1-5.

[3] KOU, H., CHEN, Y., TANG, B., CUI, Y., SUN, F., LI, J., XUE, X. An experimental study on the mechanism of texture evolution during hot-rolling process in a $\beta$ titanium alloy. Journal of Alloys and Compounds. 2014, vol. 603, pp. 23-27.

[4] ALLUAIBI, M.H., RUSEA, A., COJOCARU, V.D. Influence of thermomechanical processing at temperatures above $\beta$-transus on the microstructural and mechanical characteristics of the Ti-6246 alloy. University Politehnica of Bucharest Scientific Bulletin Series B - Chemistry and Materials Science. 2018, vol. 80, no. 1, pp. 245-258.

[5] BANERJEE, D., Williams, J.C. Perspectives on Titanium Science and Technology. Acta Materialia. 2013, vol. 61, no. 3, pp. 844-879.

[6] MAYEUR, J.R., MCDOWELL, D.L. A three-dimensional crystal plasticity model of duplex Ti-6Al-4V. International Journal of Plasticity. 2007, vol. 23, no. 9, pp. 1457-1485.

[7] ANKEM, S., MARGOLIN, H., GREENE, Ch.A., NEUBERGER, B.W., OBERSON, P.G. Mechanical properties of alloys consisting of two ductile phases. Progress in Materials Science. 2006, vol. 51, pp. 632-709.

[8] BANERJEE, A., BALACHANDRAN, S., SUWAS, S., BANERJEE, D. Deformation behaviour of titanium alloys Ti6242 and Ti-6246. In Deformation Behavior 2016: 13th International Conference on Titanium. San Diego, California, USA, 2016, pp. 1097-1101. 